\title{
Intrapulmonary metastasis in resected pathologic stage IIIB non-small cell lung cancer: Possible contribution of aerogenous metastasis to the favorable outcome
}

Keiju Aokage, MD, a,b Genichiro Ishii, MD, ${ }^{a}$ Kanji Nagai, MD, ${ }^{b}$ Osamu Kawai, MD, ${ }^{a, b}$ Yoichi Naito, MD, a,b Takahiro Hasebe, MD, ${ }^{\mathrm{c}}$ Mitsuyo Nishimura, MD, ${ }^{\mathrm{b}}$ Junji Yoshida, MD, and Atsushi Ochiai, MD ${ }^{\mathrm{b}}$

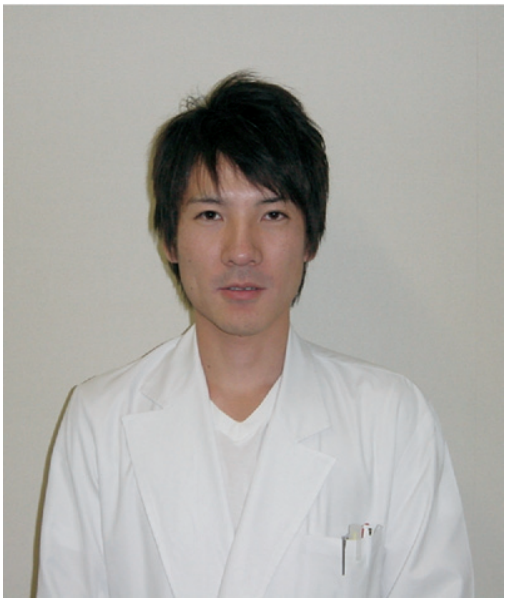

Dr Aokage
From the Pathology Division, Research Center for Innovative Oncology, ${ }^{\text {a }}$ the Division of Thoracic Oncology, ${ }^{\mathrm{b}}$ and the Clinical Laboratory Division, ${ }^{\mathrm{c}}$ National Cancer Center Hospital East, Kashiwa, Chiba, Japan.

This study was supported in part by a Grant-in-Aid for Cancer Research from the Ministry of Health, Labour and Welfare, Japan.

Received for publication Nov 8, 2006; revisions received Feb 5, 2007; accepted for publication Feb 19, 2007.

Address for reprints: Atsushi Ochiai, MD $\mathrm{PhD}$, Pathology Division, Research Center for Innovative Oncology, 6-5-1 Kashiwanoha, Kashiwa, Chiba, 277-8577, Japan (E-mail: aochiai@east.ncc.go.jp [A. Ochiai]).

J Thorac Cardiovasc Surg 2007;134:386-91

$0022-5223 / \$ 32.00$

Copyright $\odot 2007$ by The American Association for Thoracic Surgery

doi:10.1016/j.jtcvs.2007.02.048
Objective: Non-small cell lung cancer with pulmonary metastasis in the primary lobe $(\mathrm{PM}+)$ is classified as pathologic stage IIIB. Although stage IIIB PM+ indicates a poor prognosis, this stage includes various subgroups with heterogeneous clinical outcomes. The objective of this study was to extract a subgroup of patients with stage IIIB PM+ non-small cell lung cancer with a better prognosis and assess their biological characteristics and metastatic mechanisms.

Methods: We reviewed 122 cases of surgically resected stage IIIB PM+ non-small cell lung cancer and extracted a subgroup with a favorable outcome by univariate analysis of clinicopathologic factors. The 15 cases without lymph node metastasis and vessel invasion $(\mathrm{PM}+/ \mathrm{N}-/ \mathrm{VI}-)$ were extracted as the most favorable group. We assessed the clinicopathologic features of the $\mathrm{PM}+/ \mathrm{N}-/ \mathrm{VI}-$ group in comparison with the other patients with stage IIIB PM+ disease.

Results: The disease-specific survival of the $\mathrm{PM}+/ \mathrm{N}-/ \mathrm{VI}-$ group was significantly better than that of the other stage IIIB PM+ group. Microscopic characteristics of the metastatic lesions suggesting that the cancer cells had invaded via the aerogenous route were seen in $86.7 \%$ of the $\mathrm{PM}+/ \mathrm{N}-/ \mathrm{VI}-$ group, as opposed to only $9.4 \%$ of the other PM+ cases. Furthermore, in all 4 patients in the $\mathrm{PM}+/ \mathrm{N}-/ \mathrm{VI}-$ group who had a recurrence, the relapse involved intrapulmonary metastasis, rather than distant organ metastasis.

Conclusions: Stage IIIB PM+ cases via the airway route were enriched in the $\mathrm{PM}+/ \mathrm{N}-/ \mathrm{VI}-$ group and had an extremely good survival. This group should be recognized as having local disease, and if relapse occurs in the remnant lobe, it may be possible to achieve a cure by local therapy.

$\mathrm{P}$ atients with pathologic stage IIIB non-small cell lung cancer (NSCLC) have a poor prognosis even after complete resection, and they have been reported to have a $15 \%$ to $20 \% 5$-year survival. ${ }^{1-3}$ Intrapulmonary metastasis by primary NSCLC, even within the same lobe as the primary cancer, is an independent unfavorable factor and is classified as T4. Patients with intrapulmonary metastasis have been categorized as having stage IIIB disease since the revision of the TNM staging system in 1997. ${ }^{4}$ However, some investigators have reported that the prognosis of patients with intrapulmonary metastasis is more accurately reflected by classifying their disease as T3, ${ }^{5,6}$ whereas others recommend upgrading the tumor status. $^{7-9}$ Despite numerous studies, the prognostic significance of intrapulmonary metastasis is still a matter of controversy. The controversy may be attributable to the different mechanisms of intrapulmonary metastasis. Three possible mechanisms of intrapulmonary metastasis have been postulated: (1) via the lymphatic vessel route, (2) via the blood vessel route, or (3) via the airway route. ${ }^{7}$ Armed Forces Institute 


\author{
Abbreviations and Acronyms \\ NSCLC $=$ non-small cell lung cancer \\ $\mathrm{PM}=$ pulmonary metastasis \\ UICC = International Union Against Cancer
}

of Pathology text describes metastasis by the airway route as aerogenous spread. ${ }^{10}$ Two of these metastatic mechanisms, the lymphatic and hematogenous spread by cancer cells, increase the chance of remote organ metastasis. Circulating tumor cells have a greater possibility of invading distally, and several investigators have actually described a positive correlation between vessel invasion and distant metastasis or recurrence. ${ }^{11-15}$ On the other hand, a process in which tumor cells shed at the primary site implant and form a separate tumor via the airway route, namely aerogenous spread, is sometimes observed in primary lung cancer. $^{10,16}$ Therefore, NSCLC with intrapulmonary metastasis via the aerogenous route might be regarded as local disease because of the absence of systemic dissemination via lymph vessels and blood vessels.

The objective of the present study was to extract a subgroup of NSCLC patients with pathologic stage IIIB disease who have a better outcome and analyze this subgroup from the standpoint of its biological characteristics and metastatic mechanisms, especially via the airway route.

\section{Patients and Methods \\ Patient Selection}

Among the 1912 consecutive patients with NSCLC who underwent complete surgical resection at the National Cancer Center Hospital East between July 1992 and December 2004, 146 patients had pathologic stage IIIB disease, and in 122 (83.6\%) of them the diagnosis was stage IIIB disease because they had satellite modules in the same lobe as the primary lung cancer $(\mathrm{PM}+)$.

Complete resection was defined as absence of residual cancer grossly and histologically. Patients with a positive surgical margin or who underwent limited resection for NSCLC were excluded as subjects of this study. The data collection and analysis were approved by the institutional review board in January 2006, and it waived the need to obtain informed consent from each patient.

\section{Histologic Studies}

The surgical specimens were fixed with $10 \%$ formalin and embedded in paraffin. Serial 4- $\mu$ m sections were stained with hematoxylin and eosin, by the Alcian blue-periodic acid-Schiff method for cytoplasmic mucin production, and by the elastica van Gieson or Victoria blue van Gieson stain method for elastic fibers. All histologic materials included in the series were initially assessed by pathologists. The materials were subsequently reviewed by two pathologists (K.A. and G.I.) to ascertain the presence of pulmonary metastasis and assess the histopathologic features of both the
TABLE 1. Subsets of 146 patients with pathologic stage IIIB disease

\begin{tabular}{cc}
\hline Stage IIIB & No. of patients \\
\hline T4 N0 M0 & $3(2.1)$ \\
PM- & $52(35.6)$ \\
PM+ & \\
T4 N1 M0 & $5(3.4)$ \\
PM- & $16(11.0)$ \\
PM+ & \\
T4 N2 M0 & $9(6.2)$ \\
PM- & $52(35.6)$ \\
PM+ & \\
T4 N3 M0 & $0(0)$ \\
PM- & $2(1.4)$ \\
PM+ & $3(2.1)$ \\
T1 N3 M0 & $3(2.1)$ \\
T2 N3 M0 & $1(0.7)$ \\
T3 N3 M0
\end{tabular}

$P M+/-$, With/without satellite tumor nodules within the ipsilateral primarytumor lobe of the lung. Numbers in parentheses are percentages.

primary tumors and pulmonary metastases. Intrapulmonary metastasis was defined as the following features. First, there were many floating cancer cells separating from and around the primary tumor. Second, the histologic characteristics and cytologic morphology, including cell size and nuclear atypia, were similar to those of primary cancer cells. ${ }^{17}$ Lymphatic permeation was considered to be present when tumor cells floating in lymphatic vessels with no supporting smooth muscles or elastic fibers were identified. Vascular invasion was considered to be present when tumor cells floating in blood vessels with supporting elastic fibers

TABLE 2. Clinical characteristics in the 122 patients with pathologic stage IIIB PM+

\begin{tabular}{lcc}
\hline Characteristics & No. of patients & P value $^{*}$ \\
\hline Sex & & \\
$\quad$ Male & 73 & \\
$\quad$ Female & 49 & .554 \\
Age (y) & & \\
$\quad<70$ & 75 & \\
$\quad 70 \leq$ & 45 & .985 \\
Smoking history (pack-year) & & \\
$\quad<20$ & 60 & \\
$\quad 20 \leq$ & 62 & .558 \\
Smoking history & & \\
$\quad$ Never smoker & 43 & \\
$\quad$ Smoker & 79 & .402 \\
Preoperative CEA value (ng/mL) & & \\
$\quad<5.0$ & 62 & \\
$\quad 5.0 \leq$ & 60 & .123 \\
Resection & \\
$\quad$ Pneumonectomy & 7 & \\
$\quad$ Lobectomy & 115 & .235 \\
\hline
\end{tabular}

CEA, Carcinoembryonic antigen. ${ }^{*}$ Log-rank test. 
TABLE 3. Pathologic characteristics in the 122 patients with pathologic stage IIIB PM+

\begin{tabular}{lcc}
\hline Characteristics & No. of patients & $P$ value \\
\hline Dominant histologic type & & \\
$\quad$ Adenocarcinoma & 94 & .666 \\
$\quad$ Non-adenocarcinoma & 28 & \\
Differentiation & & \\
Well & 25 & .891 \\
Moderately or poorly & 97 & \\
Lymph node metastasis & & \\
N (-) & 52 & $.002 \dagger$ \\
N (+) & 70 & \\
Lymphatic permeation & & $.006 \dagger$ \\
Ly (-) & 40 & \\
Ly (+) & 82 & \\
Vascular invasion & & \\
V (-) & 36 & \\
V (+) & 86 & \\
Pleural invasion & & \\
P (-) & 62 & \\
P (+) & 60 &
\end{tabular}

${ }^{*}$ Log-rank test. $\dagger P<0.05$.

were identified. Some serial sections were stained by the Victoria blue van Gieson stain method to help recognizing elastic fibers. ${ }^{12,18}$ Histologic typing was performed according to the World Health Organization classification of cell types. ${ }^{19}$ Pathologic stage was determined on the basis of the TNM classification of the International Union Against Cancer (UICC). ${ }^{20}$

\section{Statistical Analysis}

Differences in patient characteristics between the 2 populations were tested for significance by the Pearson $\chi^{2}$ test or Fisher exact test. For the univariate analysis, all cumulative survivals were estimated by the Kaplan-Meier method, and differences in variables were calculated by the log-rank test. All $P$ values reported are 2-sided. The analyses were performed with the SPSS 11.0 statistical software program (Dr. SPSS II for Windows, standard version 11.0, SPSS Inc, Chicago, Ill).

\section{Results}

The distribution of the 146 cases classified as pathologic stage IIIB is shown in Table 1, and $122(83.6 \%)$ cases were classified as stage IIIB for the presence of intrapulmonary metastasis. Overall follow-up time of the censored patients ranged from 1.2 to 132.0 months, and the median value was 48.3 months. Univariate analysis of postoperative survival stratified according to 6 clinical and 7 pathologic factors revealed significant differences in the following factors: lymph node metastasis, vascular invasion, and lymphatic permeation (Tables 2 and 3). Among the 122 patients with $\mathrm{PM}+$ in pathologic stage IIIB, a subgroup of 15 (12.3\%) patients with a better outcome was selected according to the favorable clinicopathologic factors: no lymph node metas-
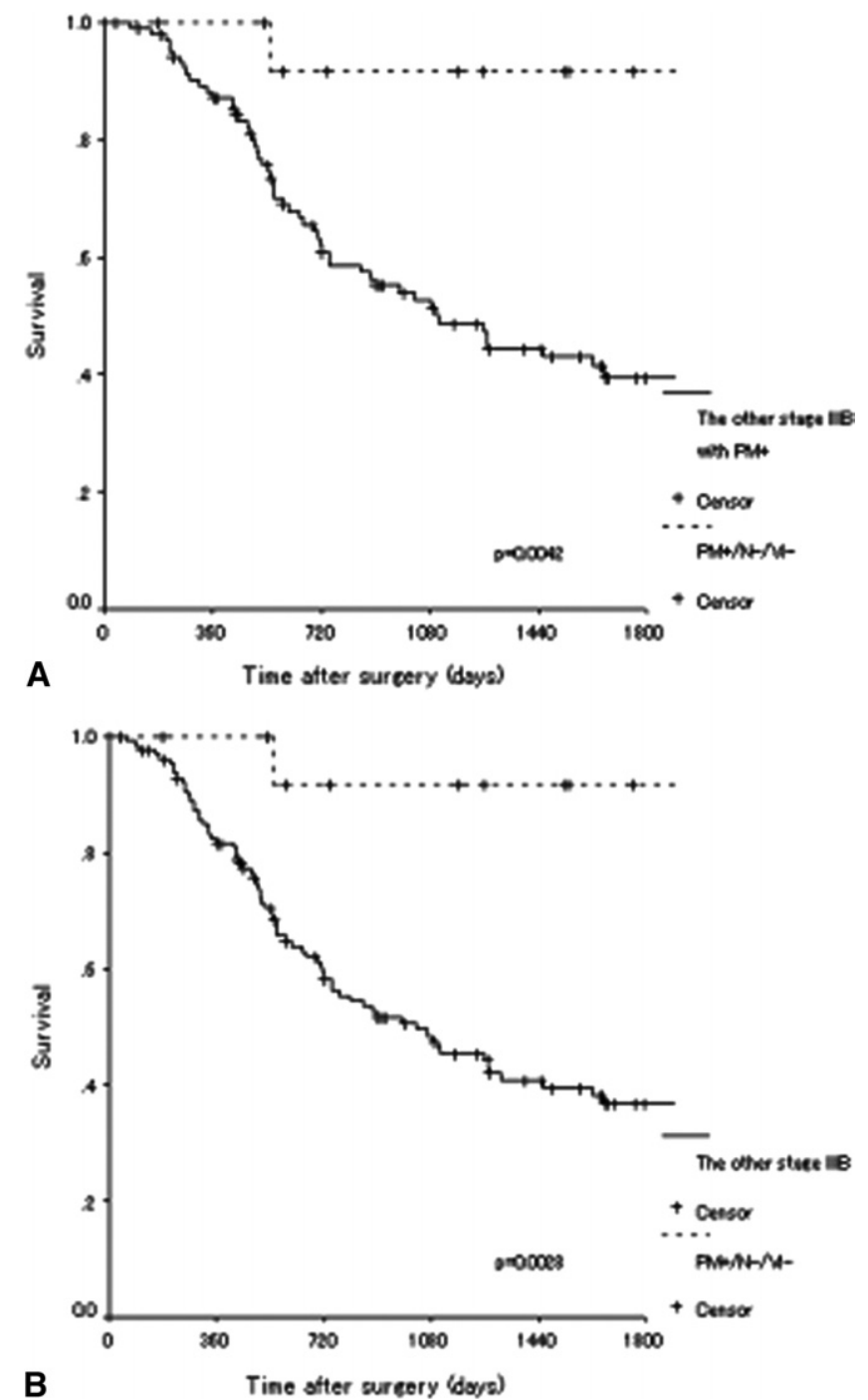

Figure 1. A, Disease-specific survival curve of the $P M+/ N-/ V I-$ group and the other stage IIIB PM+ group. B, Disease-specific survival curve of the $\mathrm{PM}+/ \mathrm{N}-\mathrm{NI}-$ group and the other stage IIIB group.

tasis $(\mathrm{N}-)$ and no vessel invasion (VI-). The survivals of this subgroup $(\mathrm{PM}+/ \mathrm{N}-/ \mathrm{VI}-)$ and the other stage IIIB $\mathrm{PM}+$ subgroup are compared in Figure 1, A. The PM+/ $\mathrm{N}-$ /VI - group had a much better outcome, that is, a $91.7 \%$ 5-year disease-specific survival, and the log-rank test showed a significant differences from the other stage IIIB $\mathrm{PM}+$ cases $(P=.0042)$. Additionally, the $\mathrm{PM}+/ \mathrm{N}-/ \mathrm{VI}-$ group also had significantly better disease-specific survival than the other stage IIIB group $(P=.0028$; Figure $1, B)$.

We considered that cancer cells with lepidic growth and no destruction of bronchovascular bundles and alveolar septa in the metastatic foci might have resulted from aerogenous spread (Figure 2, $A$ and $B$ ), ${ }^{10,16,21}$ whereas cancer 

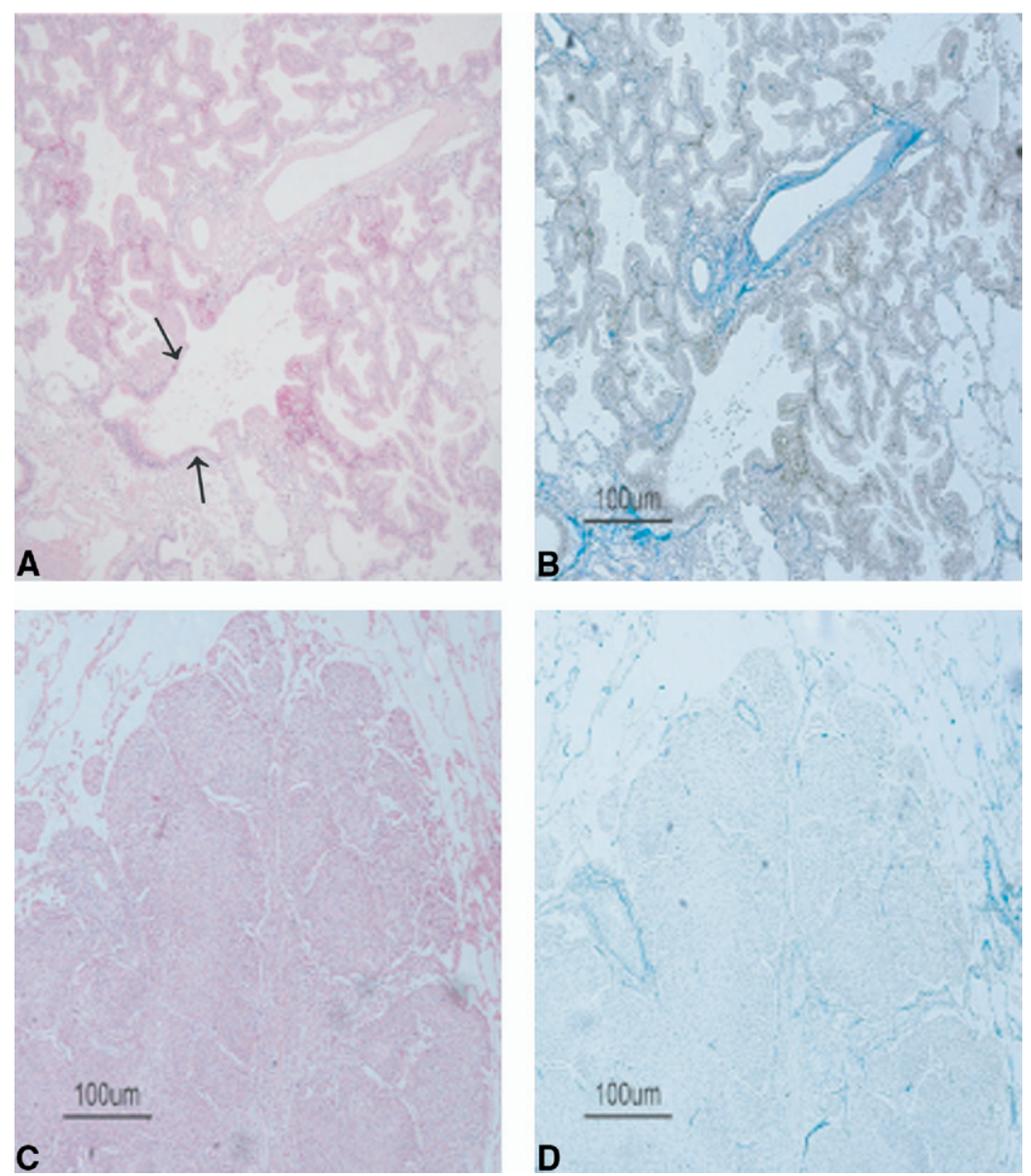

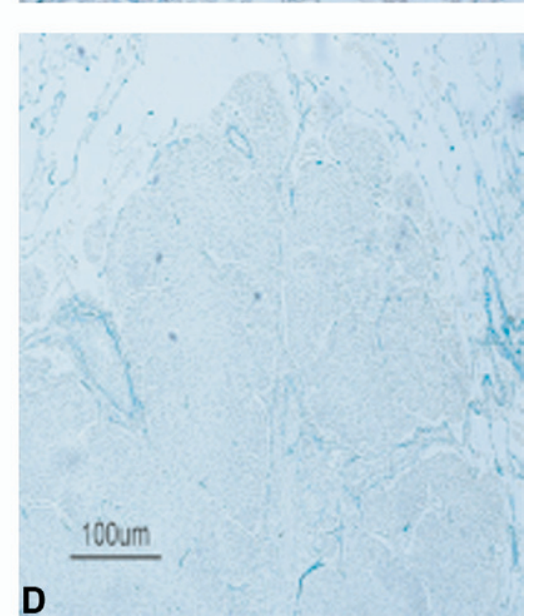

Figure 2. Histopathologic features of a tumor that metastasized by aerogenous spread. A, Cancer cells with lepidic growth but no destruction of bronchovascular bundles and alveolar septa in the metastatic foci. The black arrows point to normal bronchial epithelium adjacent to the cancer cells (hematoxylin-eosin stain; original magnification, $\times 40$ ). $B$, Higher magnification view of part $A$. Elastic fibers of the alveolar septa can be clearly seen, indicating the absence of destruction of the pulmonary parenchyma. (Victoria blue van Gieson stain; original magnification, $\times 40$ ). C, Cancer cells have formed a solid nest and destroyed the pulmonary parenchyma (hematoxylineosin stain; original magnification, $\times 40$ ). D, Higher magnification view of part $\boldsymbol{C}$. Prominent disruption of elastic fibers is seen, indicating destruction of the pulmonary parenchyma (Victoria blue van Gieson stain; original magnification, $\times 40$ ). cells that had formed solid nests and destroyed neighboring alveolar septa as they grew (Figure 2, $C$ and $D$ ) had not resulted from aerogenous metastasis. Table 4 shows the frequency of the characteristic histologic findings of aerogenous spread in the metastatic cancers. Significantly higher rates of histologic findings of aerogenous spread were found in the $\mathrm{PM}+/ \mathrm{N}-/ \mathrm{VI}-$ group $(86.7 \%)$ than in the other stage IIIB PM+ group $(9.4 \% ; P<.001)$.

Comparisons of the clinicopathologic characteristics of the $\mathrm{PM}+/ \mathrm{N}-/ \mathrm{VI}-$ group and the other stage IIIB PM+

TABLE 4. Histopathologic feature of pulmonary metastatic foci with pathologic stage IIIB

\begin{tabular}{lccc}
\hline $\begin{array}{l}\text { Lepidic growth without } \\
\text { destruction of }\end{array}$ & \multicolumn{2}{c}{$\begin{array}{c}\text { Patients with pathologic } \\
\text { stage IIIB PM+ } \mathbf{( n = 1 2 2 )}\end{array}$} & \\
\cline { 2 - 3 } $\begin{array}{l}\text { bronchovascular bundles } \\
\text { (Figure 2, } \boldsymbol{A} \text { and } \boldsymbol{B})\end{array}$ & $\begin{array}{c}\mathrm{PM}+/ \mathbf{N}-\mathbf{N I}- \\
(\mathbf{n}=\mathbf{1 5})\end{array}$ & $\begin{array}{c}\text { The others } \\
(\mathbf{n}=107)\end{array}$ & $\boldsymbol{P}$ value $^{*}$ \\
\hline Positive & $13(86.7)$ & $10(9.4)$ & $<.001$ \\
Negative & $2(13.3)$ & $97(90.7)$ & \\
\hline
\end{tabular}

*Fisher exact test; Numbers in parenthesis are percentages. group are summarized in Table 5. Compared with the other stage IIIB $\mathrm{PM}+$ group, the $\mathrm{PM}+/ \mathrm{N}-/ \mathrm{VI}-$ group contained a higher percentage of women $(P=.005)$, a lower percentage of smokers $(P=.007)$, had a lower serum carcinoembryonic antigen level $(P=.016)$, a higher incidence of well-differentiated tumors $(P<.001)$, and a lower rate of pleural invasion $(P=.003)$. These factors were not significant prognostic factors by univariate analysis among stage IIIB PM+ patients indicated in Tables 2 and 3. The histologic type of primary tumors in the $\mathrm{PM}+1$ $\mathrm{N}-/ \mathrm{VI}-$ group was adenocarcinoma in every case $(P=$ .021). Four were the mucinous bronchioloalveolar carcinoma dominant subtype and 11 were the papillary dominant subtype.

All 4 of the 15 patients with recurrence had pulmonary metastasis in the remnant lung and no distant metastases despite having stage IIIB disease.

\section{Discussion}

This study is the first report identifying the favorable subset within stage IIIB and PM+ patients and analyzing its char- 
TABLE 5. Characteristic comparison of 15 patients with $\mathrm{PM}+/ \mathrm{N}-\mathrm{NI}-$ and the other 107 patients with pathologic stage IIIB PM+

\begin{tabular}{|c|c|c|c|}
\hline \multirow[b]{2}{*}{ Characteristics } & \multicolumn{2}{|c|}{$\begin{array}{l}\text { Patients with pathologic } \\
\text { stage IIIB PM+ }(n=122)\end{array}$} & \multirow[b]{2}{*}{$P$ value ${ }^{*}$} \\
\hline & $\begin{array}{c}P M+/ N-/ V I- \\
(n=15)\end{array}$ & $\begin{array}{l}\text { The others } \\
(n=107)\end{array}$ & \\
\hline Sex & 4 & 69 & \\
\hline \multicolumn{4}{|l|}{ Male } \\
\hline Female & 11 & 38 & $.005^{*}$ \\
\hline \multicolumn{4}{|l|}{ Age (y) } \\
\hline$<70$ & 7 & 70 & \\
\hline $70 \leq$ & 8 & 37 & $.159 *$ \\
\hline \multicolumn{4}{|l|}{$\begin{array}{l}\text { Smoking history } \\
\text { (pack-year) }\end{array}$} \\
\hline$<20$ & 13 & 47 & \\
\hline $20 \leq$ & 2 & 60 & $.002^{*}$ \\
\hline \multicolumn{4}{|l|}{ Smoking history } \\
\hline Never smoker & 10 & 33 & \\
\hline Smoker & 5 & 74 & $.007^{*}$ \\
\hline \multicolumn{4}{|l|}{$\begin{array}{l}\text { Preoperative CEA value } \\
\text { (ng/ml) }\end{array}$} \\
\hline$<5.0$ & 12 & 50 & \\
\hline $5.0 \leq$ & 3 & 57 & $.016^{*}$ \\
\hline \multicolumn{4}{|l|}{ Resection } \\
\hline Pneumonectomy & 2 & 5 & \\
\hline Lobectomy & 13 & 102 & $.206 \dagger$ \\
\hline \multicolumn{4}{|l|}{ Dominant histologic type } \\
\hline Adenocarcinoma & 15 & 79 & \\
\hline Nonmucinous BAC & 0 & 32 & \\
\hline Mucinous BAC & 4 & 1 & \\
\hline Acinar & 0 & 6 & \\
\hline Papillary & 11 & 27 & \\
\hline SA with mucin & 0 & 13 & \\
\hline Nonadenocarcinoma & 0 & 28 & $.021 \dagger$ \\
\hline \multicolumn{4}{|l|}{ Differentiation } \\
\hline Well & 10 & 15 & \\
\hline Moderately or poorly & 5 & 92 & $<.001 \dagger$ \\
\hline \multicolumn{4}{|l|}{ Pleural invasion } \\
\hline$P(-)$ & 13 & 49 & \\
\hline$P(+)$ & 2 & 58 & $.003^{*}$ \\
\hline
\end{tabular}

CEA, Carcinoembryonic antigen; $B A C$, bronchioloalveolar carcinoma; $S A$ solid adenocarcinoma. ${ }^{*}$ Pearson $\chi^{2}$ test. FFisher's exact test.

acter by careful histologic examination. The $\mathrm{PM}+/ \mathrm{N}-/ \mathrm{VI}-$ group that we extracted had significantly better diseasespecific survival than the other pathologic stage IIIB PM+ patients $(91.7 \%$ vs $44.5 \%)$. Their survival was almost the same as or better than that of patients with pathologic stage IA disease. ${ }^{2,3}$ Of course, this group had a significantly better outcome than had the patients with pathologic stage IIIB disease. This subgroup as a whole had the biological characteristics described below.

First, the clinicopathologic background of this subgroup was clearly different from that of the other stage IIIB PM+ groups. It contained a significantly higher percentage of women, a lower percentage of smokers, and a higher percentage of well-differentiated tumors. All of the primary tumors were adenocarcinoma, and the dominant subtypes were mucinous bronchioloalveolar carcinoma in 4 cases and papillary subtype adenocarcinoma in 11 .

Second, the microscopic findings characteristic of aerogenous metastasis were significantly more common in the $\mathrm{PM}+/ \mathrm{N}-/ \mathrm{VI}-$ group. $^{10,21}$

Third, all 4 patients who had a recurrence among the 15 patients in the $\mathrm{PM}+/ \mathrm{N}-/ \mathrm{VI}-$ group had pulmonary metastasis in the remnant lung and no distant metastasis, despite having stage IIIB disease.

On the basis of these results, we speculated that pulmonary metastasis of the $\mathrm{PM}+/ \mathrm{N}-/ \mathrm{VI}-$ group might be caused by the mechanism of aerogenous metastasis, and this group would indicate extremely good survival. The major mechanism of metastasis of primary adenocarcinoma of the lung to the lung includes hematogenous and/or lymphatic spread. However, unlike other organs targeted as the metastatic site, the lung displays characteristic anatomic structure, which causes another metastatic mechanism-aerogenous spread. The molecular biological mechanism of this pathway has been elucidated by Kodama and associates. ${ }^{16}$ They clearly showed the important role of laminin 5 expression in aerogenous spread and lepidic growth by adenocarcinoma cells in an animal model and in resected human lung carcinomas. This molecular approach has provided insight into the mechanism of aerogenous spread in the $\mathrm{PM}+/ \mathrm{N}-/$ VI- group. Although the current data suggest a biological basis for aerogenous spread, this mechanism remains incompletely proven. However, we consider that this study will be important to investigate the further biological mechanisms of aerogenous metastasis.

NSCLC with intrapulmonary metastasis to the primary lobe via the airway route should be regarded as local disease, not as systemic disease. Thus, it might be better to classify the $\mathrm{PM}+/ \mathrm{N}-/ \mathrm{VI}-$ group as having local disease, not systemic disease. This subgroup should be clearly differentiated from other stage IIIB groups.

\section{Conclusions}

In the present study, we were able to extract a subgroup $(\mathrm{PM}+/ \mathrm{N}-/ \mathrm{VI}-)$ with an extremely good outcome from patients undergoing surgically resected NCSLC with pathologic stage IIIB disease. This $\mathrm{PM}+/ \mathrm{N}-/ \mathrm{VI}-$ group is classified as having stage IIIB disease, but because the pulmonary metastasis in this group appears to occur via the airway route, this group should be regarded as having local disease. The efficacy and role of postoperative adjuvant chemotherapy in the treatment of patients having surgically resected NSCLC with pathologic stage IIIB disease remains unclear, but some researchers recommend adjuvant chemotherapy 
after surgery. ${ }^{2-24}$ Although a prospective study with a larger number of patients in a multicenter study is warranted, it might be considered that this population is highly curable by local therapy alone without systemic adjuvant therapy. Additionally, if relapse occurs in the remnant lobe, there may be a possibility of cure by local therapy if pulmonary function permits.

\section{References}

1. Fang D, Zhang D, Huang G, Zhang R, Wang L, Zhang D. Results of surgical resection of patients with primary lung cancer: a retrospective analysis of 1,905 cases. Ann Thorac Surg. 2001;72:1155-9.

2. Goya T, Asamura H, Yoshimura H, Kato H, Shimokata K, Tsuchiya R, et al. Prognosis of 6644 resected non-small cell lung cancers in Japan: a Japanese lung cancer registry study. Lung Cancer. 2005;50:227-34.

3. Naruke T, Tsuchiya R, Kondo H, Asamura H. Prognosis and survival after resection for bronchogenic carcinoma based on the 1997 TNMstaging classification: the Japanese experience. Ann Thorac Surg. 2001;71:1759-64.

4. Mountain CF. Revisions in the International System for Staging Lung Cancer. Chest. 1997;111:1710-7.

5. Deslauriers J, Brisson J, Cartier R, Fournier M, Gagnon D, Piraux M, et al. Carcinoma of the lung: evaluation of satellite nodules as a factor influencing prognosis after resection. J Thorac Cardiovasc Surg. 1989; 97:504-12.

6. Kameyama K, Huang CL, Liu D, Okamoto T, Hayashi E, Yamamoto Y, et al. Problems related to TNM staging: patients with stage III non-small cell lung cancer. J Thorac Cardiovasc Surg. 2002;124:503-10.

7. Urschel JD, Urschel DM, Anderson TM, Antkowiak JG, Takita H. Prognostic implications of pulmonary satellite nodules: are the 1997 staging revisions appropriate? Lung Cancer. 1998;21:83-7; discussion 9-91.

8. Yano M, Arai T, Inagaki K, Morita T, Nomura T, Ito H. Intrapulmonary satellite nodule of lung cancer as a T factor. Chest. 1998;114: 1305-8.

9. Okada M, Tsubota N, Yoshimura M, Miyamoto Y, Nakai R. Evaluation of TMN classification for lung carcinoma with ipsilateral intrapulmonary metastasis. Ann Thorac Surg. 1999;68:326-30; discussion 31.

10. Colby T, Koss M, Travis W. Tumors of the lower respiratory tract. 3rd ed. Washington DC: Armed Forces Institute of Pathology; 1994.

11. Macchiarini P, Fontanini G, Hardin MJ, Chuanchieh H, Bigini D, Vignati S, et al. Blood vessel invasion by tumor cells predicts recurrence in completely resected T1 N0 M0 non-small cell lung cancer. J Thorac Cardiovasc Surg. 1993;106:80-9.
12. Gabor S, Renner H, Popper H, Anegg U, Sankin O, Matzi V, et al. Invasion of blood vessels as significant prognostic factor in radically resected T1-3N0M0 non-small-cell lung cancer. Eur J Cardiothorac Surg. 2004;25:439-42.

13. Fu XL, Zhu XZ, Shi DR, Xiu LZ, Wang LJ, Zhao S, et al. Study of prognostic predictors for non-small cell lung cancer. Lung Cancer. 1999;23:143-52.

14. Brechot JM, Chevret S, Charpentier MC, Appere de Vecchi C, Capron $\mathrm{F}$, Prudent J, et al. Blood vessel and lymphatic vessel invasion in resected nonsmall cell lung carcinoma. Correlation with TNM stage and disease free and overall survival. Cancer. 1996;78:2111-8.

15. Fujisawa T, Yamaguchi Y, Saitoh Y, Hiroshima K, Ohwada H. Blood and lymphatic vessel invasion as prognostic factors for patients with primary resected nonsmall cell carcinoma of the lung with intrapulmonary metastases. Cancer. 1995;76:2464-70.

16. Kodama K, Ishii G, Miyamoto S, Goya M, Zhang SC, Sangai T, et al. Laminin 5 expression protects against anoikis at aerogenous spread and lepidic growth of human lung adenocarcinoma. Int $J$ Cancer. 2005;116:876-84.

17. Martini N, Melamed MR. Multiple primary lung cancers. $J$ Thorac Cardiovasc Surg. 1975;70:606-12.

18. Saijo T, Ishii G, Ochiai A, Hasebe T, Yoshida J, Nishimura M, et al. Evaluation of extratumoral lymphatic permeation in non-small cell lung cancer as a means of predicting outcome. Lung Cancer. 2007; 55:61-6.

19. Travis W, Colby T, Corrin B, Shimosato Y, Brambilla E. Histological typing of lung and pleural tumors. 3rd ed. Berlin: Springer Verlag; 1999.

20. Sobin L, Wittekind C, International Union Against Cancer. TNM classification of malignant tumors. 5th ed. New York: Wiley-Liss; 1997.

21. Gaeta M, Blandino A, Pergolizzi S, Mazziotti S, Caruso R, Barone M, et al. Patterns of recurrence of bronchioloalveolar cell carcinoma after surgical resection: a radiological, histological, and immunohistochemical study. Lung Cancer. 2003;42:319-26.

22. Arriagada R, Bergman B, Dunant A, Le Chevalier T, Pignon JP, Vansteenkiste J. Cisplatin-based adjuvant chemotherapy in patients with completely resected non-small-cell lung cancer. $N$ Engl J Med. 2004;350:351-60.

23. Hotta K, Matsuo K, Ueoka H, Kiura K, Tabata M, Tanimoto M. Role of adjuvant chemotherapy in patients with resected non-small-cell lung cancer: reappraisal with a meta-analysis of randomized controlled trials. J Clin Oncol. 2004;22:3860-7.

24. Lee SW, Choi EK, Chung WK, Shin KH, Ahn SD, Kim JH, et al. Postoperative adjuvant chemotherapy and radiotherapy for stage II and III non-small cell lung cancer (NSCLC). Lung Cancer. 2002; $37: 65-71$. 